\title{
La Inquisición ante la pérdida de Gibraltar
}

\author{
Antonio Domínguez Ortiz
}

El 4 de Agosto de 1704 el almirante Rooke arrancó la bandera de España y clavó la británica en Gibraltar. Con esta acción abría un contencioso aún no liquidado, causaba a la Monarquía Hispánica una grave afrenta y creaba también un conflicto no pequeño a la Inquisición española; acerca de este último punto puedo ofrecer algunos datos extraídos del ingente fondo documental que custodia el Archivo Histórico Nacional de Madrid.

Antes de la ocupación inglesa Gibraltar era una ciudad andaluza cuya población, mentalidad e instituciones en nada se diferenciaban de las del resto de Andalucía. A pesar de su estratégica situación no había crecido de forma considerable; hay pruebas de que a medidados del siglo xvII atravesó una gravísima crisis, y aunque después se recuperase algo no debía superar los cuatro mil habitantes en el momento de la invasión ${ }^{1}$. A pesar de su pequeñez tenía una parroquia, tres conventos de frailes, uno de monjas, un hospital de San Juan de Dios y varias ermitas; testimonio irrefragable de que los gibraltareños, en punto a la religiosidad, no se diferenciaban nada del resto de los españoles. Otro argumento probatorio es que entre 1593 y 1703 recibieron órdenes mayores o menores 156 gibraltareños de manos del obispo de Cádiz, a cuya diócesis pertenecían $^{2}$. El catolicismo de la población no sólo era sólido sino excesivo; no faltó, por ejemplo, quien denunciara al obispo que había mujeres que tenían abandonada su casa por asistir con asiduidad al confesionario ${ }^{3}$.

\footnotetext{
Es la población que le calcula para comienzos del xvIII López de Ayala (Historia de Gibraltar, pág. 44. Madrid, 1782).

2 SOLÉ, Pablo Antón, Catálogo de los papeles referentes a Gibraltar en el Archivo Diocesano de Cádiz.

3 SOLÉ, P. A., op. cit, 1 doc. 14 - 143.
} 
Otro rasgo propio de la época era la multiplicidad de jurisdicciones; la civil, la militar y la eclesiástica, que era doble: por una parte la del Ordinario; por otra, la Inquisitorial, de suerte que un amancebado podía ser denunciado por el vicario, el visitador episcopal y el familiar del Santo Oficio. Para la Inquisición Gibraltar era una plaza que requería especial vigilancia, por ser puerto frecuentado por extranjeros y tener enfrente a Ceuta, ciudad en la que, a pesar de ser española, se toleraba la existencia de una aljama de judíos; otros llegaban a ella de Tetuán y otros puntos de Marruecos, y algunos se aventuraban a cruzar el Estrecho y entrar en España con diversos pretextos; el más común, el de querer ser instruidos en la fe cristiana y bautizados. En estos casos, el comisario del Santo Oficio en Gibraltar los remitía a Sevilla ${ }^{4}$ y el Tribunal de esta ciudad daba cuenta a la Suprema, que indicaba la conducta a seguir. Pocos meses antes de la invasión británica el notario del Santo Oficio en Gibraltar enviaba carta, acompañada de otra del guardián del convento de capuchinos de Salé, notificando la llegada de una familia de hebreos que abrigaba dicha intención ${ }^{5}$. Otros se presentaban en demanda de lo que podríamos llamar "admisión temporal», o diciendo que tenían que comunicar noticias de gran interés para el gobierno español. Atendiendo a esta realidad, y de acuerdo con la obsesión antijudía que se había apoderado de las mentes españolas, en el Tratado de Utrecht las cláusulas relativas a la cesión de Gibraltar comportaban, junto con el respeto a la religión católica de sus habitantes, el compromiso británico de no consentir la presencia de judios en la plaza. Entre 1717 y 1718 debían haber llegado rumores a la Suprema de que, en contravención con el tratado, había judios en Gibraltar; los inquisidores de Sevilla, tras las averiguaciones pertinentes, aseguraron que sólo quedaban dos que estaban arreglando los papeles para irse. Los demás habían emigrado ya a Amsterdam o a Liorna ${ }^{6}$.

Antes de dicha fecha, en 1712, habían llegado órdenes de Madrid a los inquisidores sevillanos para que informasen acerca de la situación del catolicismo en Gibraltar; aún no se habían estipulado las garantías concertadas en Utrecht y las noticias que llegaban eran alarmantes; la conquista había ido acompañada de las violencias habituales; no hubo matanzas, pero sí saqueos y profanaciones. La mayoría de los vecinos huyeron a San Roque y otros lugares próximos; otros se quedaron o volvieron; entre los primeros, el párroco de Santa María la Coronada, que estimó su deber permanecer entre sus fieles, sumido en el más profundo

Gibraltar pertenecía al distrito inquisitorial hispalense como parte del obispado de Cádiz. AHN, Inquisición, 3.022. Carta de Sevilla a la Suprema en 30 de octubre de 1703.

AHN, Inquisición, 3.033. Folios sin numerar. 
dolor («Muchas veces, barriendo los ladrillos de esta sagrada iglesia, regué el suelo con agua de mis ojos»). En cambio, el comisario inquisitorial, Francisco Antonio Avejero y Avendaño, huyó, abandonando toda su hacienda, por lo que comunicó a sus superiores que se hallaba en total indigencia ${ }^{?}$.

En 1712, fracasados los intentos de reconquistar Gibraltar, ya se extendía el temor de que la pérdida de aquella plaza fuera definitiva. El Consejo de la Suprema quería tener información fidedigna acerca de la situación religiosa en Gibraltar y transmitió la orden al Tribunal de Sevilla. Éste, como no había ya ningún ministro de la Inquisición en aquella ciudad, se dirigió a los comisarios de Cádiz, Medina Sidonia, El Puerto de Santa María y Tarifa. Tenemos sus respuestas, que arrojan bastante luz no sólo acerca del clero y culto católicos sino sobre otros particulares de la situación en Gibraltar poco antes de ser desmembrado por un tratado internacional de la Madre Patria ${ }^{8}$.

La petición de informes trasmitida a los comisarios indicaba que debían suministrar datos sobre los siguientes extremos:

«Estado que tienen en Gibraltar las cosas de nuestra sagrada religión; si han quedado algunos cathólicos y ministros del Santo Oficio; cómo y en qué forma pública o secreta se les permiten o no sacerdotes, templos, en que libremente puedan concurrir a decir y oir misa y administrar los sacramentos, o si se les prohibe y molestan por esa causa, o si procuran perbertirlos y atraerlos a sus herrores. Qué comercio tienen allí los ingleses, y si con ese motivo entran tierra adentro, y hasta donde. $Y$ si se an experimentado ycombenientes con su comunicación en los lugares zercanos en lo espiritual y en lo temporal; o si conteniéndose en el recinto de la plaza introducen en ella libros de su falsa doctrina, y disponer y facilitar la entrada de todo lo que pueda ser perjudicial a nuestra sancta fee; y qué providencia podrá darse para al remedio de tan grave daño, con todo lo demás que se le ofreciere y pareciere en orden al más seguro resguardo y conserbación y pureza, procurando el comisario ejecutar estas diligencias con todo recato y secreto, encargándolo a las personas de quien tomasen información, y que sean las mas fidedignas y noticiosas de lo que aya sucedido en dicha plaza, y entre ellas valiéndose del superior que hubiere de los convetos de San Francisco de la Observancia y de los descalzos de dicha religión, y de los mercenarios descalzos, aviéndolos en dicha ciudad, por quanto en dicha plaza antes que se

AHN, Inquisición, 3022, carta de 6 de octubre de 1704. La Suprema ordenó a los inquisidores de Sevilla que favorecieran a Avejero encomendándole informaciones de limpieza de sangre "y demás negocios que puedan darle alguna utilidad».

${ }_{8}$ Los documentos utilizados se encuentran en el legajo 3.026 de la sección Inquisición del Archivo Histórico Nacional, sin numeración. 
perdiese avia dichos tres conventos, y respecto de hallarnos con noticia de que quando se perdió dicha plaza se quedó en ella el vicario eclesiástico con permiso del prelado, podrá el comisario informarse de su Ilma. y si al dicho vicario se le han remitido a sus tiempos los Santos Óleos, y si se ha conservado el convento de religiosas clarisas. Lo qual executará con la mayor brevedad...” etc.

El bloqueo terrestre que sostenían las harto débiles fuerzas españolas en torno al Peñón no debía ser muy eficaz, porque los interrogados conocían perfectamente lo que ocurría en su interior y contestaron con diligencia: Sevilla les dirigió este interrogatorio el 27 de julio, y entre el 31 del mismo mes y el 2 de agosto enviaban los comisarios sus respuestas a Sevilla y muy pocos días después eran recibidas en la Corte. El informe más breve era el de Juan García de la Yedra, comisario del Santo Oficio en Cádiz. Expresaba en él que había tomado noticias de varias personas, unas gibraltareñas, otras que siendo vecinos de Cádiz tenían negocios o propiedades en aquella plaza, en especial el chantre de la catedral, natural de Gibraltar y con propiedades rústicas en su término que visitaba cada año. De su testimonio se deduce que todos los conventos estaban cerrados y destinados a otros usos; solamente en el de los franciscanos observantes que servía de alojamiento al gobernador inglés, permanecian dos religiosos, uno valenciano y otro de Toledo, que decían misa en su iglesia, aunque el retablo e imágenes estaban maitratados. Los demás conventos y ermitas (entre las que señala, por la gran devoción que siempre suscitó entre los gibraltareños la de Nuestra Señora de Europa):

"han servido y sirven de almacenes para viveres, sin que sus igiesias tengan culto alguno, incluso el de las religiosas clarisas, que salieron quando se rindió la plaza. En el de San Juan de Dios cuidan sus enfermos. La parroquia se mantiene, y en ella se ejercita el Divino Culto públicamente, administrándose todos los santos sacramentos como antes de la pérdida de la plaza al número de cien personas españolas que habrá en ella, introduciéndose desde el Campo los santos óleos, y está ejerciendo de párroco y vicario Don Juan Romero de Figueroa, natural de la misma ciudad, cura que to era antes y eclesiástico de ejemplar zelo, sacrificando su vida en servicio de la religión; tiene por compañero y párroco a D. Joseph de la Peña, natural de la misma ciudad, y ay en ella D. Juan Conde, presbítero natural de Cartagena de Levante ${ }^{9}$. También asiste en el convento de la Merced fray Juan Núñez".

«No se permite por el Governador que ingleses ni irlandeses católicos asistan a nuestra iglesia ni profesen públicamente nuestra santa fe. Tienen un ministro protestante de ración francesa, hugonote, que enseña pú-

\footnotetext{
9 La Cartagena de Murcia, por oposición a Cartagena de Indias.
} 
blicamente la secta protestante y hace sus ejercicios en la pieza del refectorio del convento de San Francisco".

"Ay en dicha plaza hasta cien familias de hebreos, a quienes se les permite y tienen su sinagoga".

"Son muchos los moros que en la referida plaza ay frecuentemente, aunque asta aora no se les ha dado mezquita".

«No se a observado asta ahora particular aplicación del ministro protestante a combertir nuestros cathólicos, aunque el riesgo se considera gravísimo, como la ocasión de introducir libros y cartillas de sus falsos dogmas».

«El comercio que dicha plaza mantiene es grande con Berbería, y de Málaga es considerable el que ay. Asta aquí han efectuado desde la plaza diferentes entradas sobre una y otra costa para el pillaje de los ganados sin hazer asiento».

«El gravísimo y nunca ponderable daño que puede padezerse en lo espiritual y temporal no restituida esta plaza se funda en la docilidad de genios de los moradores de todos los pueblos inmediatos a la plaza, la astucia de los sećretarios y hebreos y natural flaqueza que apetece la libertad, y en lo temporal, siendo ciudad del continente de nuestra España, que la situación y naturaleza tanto lo a fortificado, que tanto podrá adelantarla el gran comercio que mantendrán en ella, son todas fuerzas muy considerables contra nosotros mismos».

La solución que se le ocurre al comisario informante para prevenir o aminorar tales daños es curiosa:

«Si la quietud de Europa necesita de que se sacrifique esta parte, no hallo medio de evitar el gran daño a que $V$. Ilma. intenta ocurrir, y sólo podría ser menor si el Govierno en lo político fuese español, siendo estraño el de las armas».

O sea, (si no comprendo mal) que los ingleses mantuvieran allí guarnición y en lo demás dejaran las cosas como antes. Una curiosa idea, no del todo utópica, pues la diplomacia española no consiguió (ni intentó naturalmente) que en Gibraltar se mantuviera el aparato inquisitorial, pero sí la garantía del respeto a la Religión católica y la expulsión de los judíos que habían comenzado a afluir a la plaza.

Los informes de los otros tres comisarios coinciden en lo substancial con el anterior, aunque rectifican detalles o añaden otros. El de Gerónimo Ximénez Carrión, comisario de Medina Sidonia, dice que al producirse la entrada del enemigo salieron todos los curas excepto dos, uno «que ya es muerto» y el párroco Sr. Romero, que ejercía libremente su ministerio, incluso llevar el viático a los enfermos, «sin que se aia ofrecido inconveniente de irrisión o alguna irreverencia de los enemigos, y en el Campo se oyen las campanas». Muchos vecinos que habían salido de Gibraltar 
en los primeros momentos, volvieron después, y también algunos vecinos de lugares próximos, especialmente el año 1709 «por la falta de pan que se padeció» "10. Aunque al principio sólo mencionó dos sacerdotes, después asegura, según testimonios que ha recibido, que permanecen varios, seculares y regulares, pero sólo había culto en la parroquia y en el ermita de Nuestra Señora de Europa. «No ha quedado convento alguno, ni se mantiene religioso de los que avía en ellos».

Añade que los ingleses de la guarnición no tenían comercio ni trato con los que vivían fuera de la plaza, ni se tenía noticia de que trataran de hacer prosélitos entre los que habitaban en ella, ni que hayan introducido libros o papeles de su secta, aunque podrían hacerlo con facilidad:

"pero ellos no tratan dello, ni los cabos les permiten la salida, si no es a aquellos puestos que tienen abanzados, como son El Portel, La Torre de los Diablos y algunos otros, y aunque dominan un pedaso de terrenos que fueron huertas y llegan allí a cazar, no llegan a comerciar con los españoles porque la gente de Córdoba lo impide por aquella parte ${ }^{11} \%$.

Muchos de los vecinos que salieron de Gibraltar se aposentaron en San Roque y Los Barrios. El obispo de Cádiz había puesto un cura en cada uno de estos pueblos y en la primera había un ministro del Santo Oficio llamado D. Francisco Marín.

Desde Tarifa, D. Pablo de Mena daba más detalles acerca de los eclesiásticos que habian permanecido en la plaza después de su pérdida. Además del párroco Romero de Figueroa asistió en los primeros tiempos D. Juan Asensio (?) Roman que murió. En el convento de San Francisco de la Observancia quedaron tres religiosos, dos sacerdotes, fray Antonio de las Casas y un fray Baltasar de cuyo apellido no se acordaba, y un lego. Los tres habían ya fallecido. En el de la Merced Calzada también quedaron tres de sus moradores; dos sacerdotes, fray Juan Nuñez, fray Baltasar López y un lego. Los tres salieron de la plaza por no poder sobrellevar los excesos que los ingleses cometían intra claustra. Allí tienen los cuarteles, y las iglesias sirven de almacenes, y lo mismo sucede en los demás templos, excepto en el de San Francisco y en la parroquia. Todos los referidos clérigos y religiosos quedaron en la plaza por orden

10 La esterilidad, hambre y epidemias del año 1709 (extendidas en otras regiones españolas hasta el de 1711) fueron espantosas. Véase mi Sociedad y Estado en el siglo xvIII español, capítulo II.

11 Ocupados los ejércitos francoespañoles en la campaña de Cataluña se situaron ante Gibraltar milicias de Córdoba y otras provincias andaluzas de muy bajo nivel combativo. Error que se pagó muy caro. 
de sus superiores a fin de mantener aquellos santuarios, y en ellos dar a Dios el culto debido y administrar a los fieles los santos sacramentos.

Añade que quedaron otros clérigos en la plaza, entre ellos Don Joseph de Peña, que era colector de aquellas iglesias, de quien no se sabe faltara a su obligación de católico aunque ejerció por algún tiempo el ministerio de repartir entre los españoles las raciones de harina por orden del gobernador inglés. Otro religioso que en cierto modo fue colaborador, aunque ignoramos los detalles y circunstancias, fue un religioso mercedario llamado fray Gaspar de la Soledad, de quien el informante dice: «No se sabe faltara al cumplimiento de sus obligaciones católicas», pero observó una conducta política sospechosa, ambigua; se fue con los ingleses a Barcelona, después volvió a Andalucía, donde fue preso por los religiosos de su propia Orden y castigado rigurosamente. «Aunque se dijo que havía muerto no se save de sierto». Sigue el elogio del párroco Don Juan Romero, de su ejemplo, doctrina e intrepidez. Supo que algunos herejes se introducian durante la celebración de las misas y cometían irreverencias, cerró todas las puertas a excepción de un postigo y fue a quejarse al gobernador.

"Sus exercicios son rezar el rosario, decir misa, administrar los santos sacramentos dentro de la iglesia y a los enfermos llevarles el viático y la santa unción con gran sigilo, llebando a Jesucristo en el pecho sin luz ni campanilla a fin de evitar la irrisión de los herejes, como lo hacían a la hora de tocar a misa los domingos y días de fiesta, tocar a las ánimas y la oración angelical».

Tenía noticias el informante de haber entrado en Gibraltar capuchinos, franciscanos observantes y de otras religiones, que no sabía quienes eran, ejerciendo su ministerio en el convento de San Francisco, en el cual tenía también su residencia el gobernador, y en la Sala De Profundis tienen los herejes su sinagoga, (sic) "cometiéndose en esta casa los feos y execrables delitos que $V$. $^{a}$ Ilma. ${ }^{a}$ puede considerar». No se tenía noticia de que algunos de los fieles católicos hayan faltado a su obligación, ni que asistieran sacerdotes ni fieles al bautizo del hijo de un protestante, que se celebró en San Francisco con gran ruido de campanas.

La fidelidad de los habitantes a su fe católica le parecía más notable al comisario porque no había quedado en la plaza ningún ministro de la Inquisición, que pudiera delatarlos y por la variedad de gentes que allí se habian establecido: ingleses, holandeses, irlandeses, escoceses, genoveses, judíos, moros, catalanes, napolitanos, mallorquines, valencianos. No había franceses. El comercio lo hacen con Berbería, no con nuestras costas, "a excepción de los genobeses por ser neutrales». Pero añade a 
continuación que de los puertos del obispado de Málaga han ido barcos con bastimentos a Gibraltar, aunque no se tiene noticia que de esta comunicación haya resultado algún incoveniente de orden espiritual, ni introducido libros de sus falsas doctrinas, pero el peligro de que así ocurra es inminente, y se deben redoblar los esfuerzos para registrar las embarcaciones de genoveses, que es de las que puede provenir mayor daño.

Por último, el informe de D. Juan Antonio de la Peña, comisario inquisitorial de El Puerto de Santa María, insistía especialmente en aquella materia que más interesaba al Santo Oficio: la posible labor proselitista de las autoridades gibraltareñas; Peña la negaba, y con más insistencia que los anteriores. Las noticias las tomó principalmente de dos militares que asistían al cerco: Don Francisco Martínez, capitán de caballos del regimiento de la costa, y el también capitán de caballos D. Martín de Valdespina, cuyo testimonio era más valioso porque estuvo prisionero dentro de la plaza durante algunos meses. El primero aseguraba que el bloqueo era efectivo, aunque confiesa que alguna comunicación y comercio había, sobre todo por el inmediato puerto de Manilva y por industria de los genoveses, en cuyos barcos solian ir españoles a comprar y vender.

En cuanto a D. Martín de Valdespina, su testimonio era singular; había sido hecho prisionero y durante ocho meses residió en Gibraltar en calidad de tal, pero con libertad para moverse y tratar toda clase de personas, así que sus noticias eran de la máxima garantía. A la sazón estaba en territorio español, en libertad bajo palabra que dio a los ingleses de restituirse a la plaza cuando fuera llamado (restos de un estilo de milicia cabälleresca ya en desuso). Según declaró, el Gobernador no sólo garantizaba la libertad de culto a los gibraltareños católicos que acudían a la parroquia, sino que surgiendo conversación sobre esto en la mesa del gobernador, a la que había sido invitado, le dijo tener orden formal de su gobierno de no consentir molestias a los habitantes católicos so las más graves penas.

Que no eran meras palabras lo comprobó D. Martín con ocasión de haber llegado una embarcación de Portugal, y en ella diferentes sujetos, y cuando les llegó la hora de reembarcarse, dos seglares, un fraile y otro que parecía estudiante pidieron audiencia al gobernador y le manifestaron que querían reducirse a la religión anglicana,

«a que les respondió el governador que se fueran en horamala, que qué hombres podían ser ellos, pues dejaban su religión, y que al instante se embarcasen, y que si querían proseguir fuesen a Inglaterra, y así los hizo embarcar».

Confirmaba lo ya sabido acerca del culto que se ejercía en la parroquia y en la iglesia del convento de la Merced. Otros edificios estaban desti- 
nados a almacenes, y San Juan de Dios a hospital de guerra. En cuanto a impresos, no circulaba ninguno ofensivo para nuestra religión, aunque sí propaganda política favorable a los derechos del Archiduque Carlos.

La política de tolerancia religiosa con los católicos gibraltareños le venía impuesta a Inglaterra por el carácter de la Guerra de Sucesión, en la que aparecía como aliada de un príncipe católico, para el que el apoyo de fuerzas no católicas había tenido consecuencias nefastas en el espíritu de la España tradicional, presta a considerar aquélla como una guerra de religión. Por su parte, la Inquisición quedó a medias tranquilizada sobre las consecuencias que tendría la pérdida del Peñón. Era un contratiempo grave, una amenaza siempre latente pero no una llaga abierta y sangrante. Por eso, después de 1713, mientras Gibraltar y los gribaltareños siguen ampliamente representados en el Archivo Diocesano de Cádiz, ocuparon muy poco espacio en la atención del Santo Oficio. 